\title{
TRAFFIC ANALYSIS AND CAPACITY EVALUATION
}

\author{
Rajnish Kumar Rai, \\ Department of Civil Engineering \\ Delhi Technological University,
}

\author{
Rinku \\ Department of Civil Engineering \\ Delhi Technological University
}

\author{
Narad Muni Prasad \\ Asst. Professor civil engineering \\ Delhi technological University
}

\begin{abstract}
Traffic density overflow is becoming a major problem not in Delhi but all over the world. So, the requirement of estimating traffic amount in a compatible way and it is needed to improve the road facilities in order to connect different areas with no loss of time. The current studies of traffic volume characteristics of highway in front of Delhi Haat INA, New Delhi of stretch $750 \mathrm{~m}$. In the last ten years the volume oh vehicles has been increased considerably because of improved economical status of people. Highly heterogeneous traffic of vehicles of extensively changing physical and operational features with no lane discipline. In this study main focus is given on traffic volume data collection and the different analysis are carried out. The main aim of our project is to find the capacity of the road and comment on its congestion level.
\end{abstract}

Keywords: Traffic Analysis, Passenger Car Equivalent (PCE), Traffic Capacity, PCU.

\section{INTRODUCTION}

In overall economic development of a country transport plays a very significant role. Transport leads into the growth of infrastructure industrialization and massive production. The number of vehicles passing a specific cross section of a road in unit time is called the traffic density usually traffic density is computer in terms of vehicle per minute or vehicles per hour. Traffic density on a road is generally shows in terms of a standard vehicle unit and this reference is called passenger car unit. The traffic density is dynamic and changes each other in a day

Daily traffic density changes on different days in a week and different month in season of the year. In most of the developed countries important factors like vehicle composition of traffic stream flow rate, splits, peak hour flow and early mean daily traffic are applied for design planning and operating roadways.

in India under mix traffic flow it is difficult to estimate passenger car unit of various type of vehicles on two line Highway. Passenger car unit values are fixed for vehicles like cars, trucks, rickshaw, bullockcarts motorcycle etc. And these values are given by Indian road Congress and depend on traffic configuration on highways.
The traffic flow on the selected road is heterogeneous with vehicle having various static and dynamic features. By changing the different sorts of vehicles into passenger car units and finding the actual capacity of the road and then comparing it with the maximum theoretical capacity of the road we will comment on the congestion of the road.

\section{PROPOSED Algorithm}

\section{A. OBJECTIVE OF STUDY:}

THE PROJECT STUDY INCORPORATES THE FOLLOWING MAIN OBJECTIVE:

- Traffic volume survey to know the traffic flow running on the given project road section.

- Finding the actual capacity (in terms of PCU) and comparing it with the maximum theoretical capacity.

- Giving feedback on traffic congestion from the result obtained.

\section{PROJECT STRECH.}

Mahatma Gandhi Road (Inner Ring Road) in front of Dilli haat, INA, New Delhi of stretch $750 \mathrm{~m}$.It is a 2 lane road. The stretch is shown by black dots in the figure

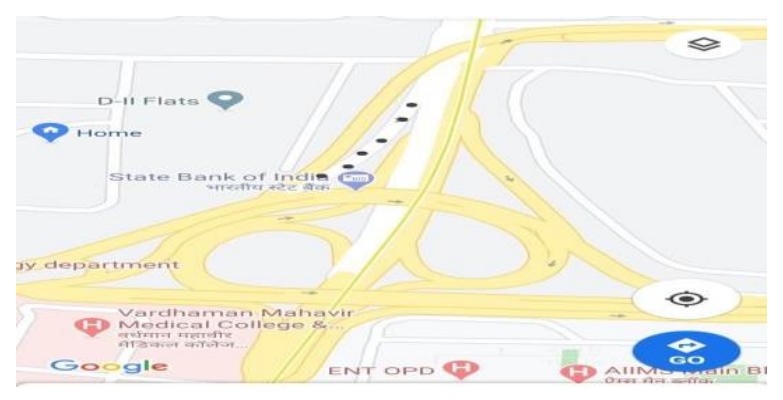

Fig1:Location of Project

\section{B. METHODOLOGY:}

1)Methodology for Traffic Volume Study on The Road.

2) Methodology of calculating average daily traffic.

3) Methodology of calculating actual capacity of road. 


\section{EXPERIMENTS AND RESULTS}

\section{TRAFFIC VOLUME SURVEY}

Duration of survey was divided into 3 slots i.e. morning (8$10 \mathrm{am})$, afternoon (1- $3 \mathrm{pm})$ and evening (6-8pm). The data were recorded on 2 days to account for variation in traffic. i.e. on $18 / 02 / 2020$ and $20 / 02 / 2020$

Note- 24 hour traffic volume study not feasible, we have to make some accurate approximations.

\begin{tabular}{|l|c|c|c|c|c|c|}
\hline Time & $\begin{array}{c}8- \\
9 \mathrm{am}\end{array}$ & $\begin{array}{c}9- \\
10 \mathrm{a} \\
\mathrm{m}\end{array}$ & $\begin{array}{c}1- \\
2 \mathrm{pm}\end{array}$ & $\begin{array}{c}2- \\
3 \mathrm{p} \\
\mathrm{m}\end{array}$ & $\begin{array}{c}6- \\
7 \mathrm{pm}\end{array}$ & $\begin{array}{c}7- \\
8 \mathrm{pm}\end{array}$ \\
\hline $\begin{array}{l}2 \text { wheele } \\
\mathrm{r}\end{array}$ & 340 & 290 & 322 & $\begin{array}{c}29 \\
4\end{array}$ & 448 & 349 \\
\hline $\begin{array}{l}4 \text { wheele } \\
\mathrm{r}\end{array}$ & 166 & 184 & 182 & $\begin{array}{c}12 \\
6\end{array}$ & 231 & 277 \\
\hline $\begin{array}{c}\text { Auto } \\
\text { ricksha } \\
\text { w }\end{array}$ & 5 & 24 & 30 & 18 & 17 & 39 \\
\hline $\begin{array}{c}\text { Bus } \\
\text { Lmv/L } \\
\text { cv }\end{array}$ & 31 & 22 & 6 & 11 & 7 & 12 \\
\hline $\begin{array}{l}\text { Others } \\
\text { (trucks } \\
\text { (10 }\end{array}$ & 0 & 0 & 0 & 0 & 0 & 0 \\
\hline Total & 552 & 533 & 553 & $\begin{array}{c}46 \\
0\end{array}$ & 709 & 684 \\
\hline
\end{tabular}

TABLE1: Day 1 count.

\begin{tabular}{|c|c|c|c|c|c|c|}
\hline Time & $\begin{array}{c}8- \\
9 \mathrm{am}\end{array}$ & $\begin{array}{c}9- \\
10 \mathrm{a} \\
\mathrm{m}\end{array}$ & $\begin{array}{c}1- \\
2 \mathrm{p} \\
\mathrm{m}\end{array}$ & $\begin{array}{c}2- \\
3 \mathrm{pm}\end{array}$ & $\begin{array}{c}6- \\
7 \mathrm{p} \\
\mathrm{m}\end{array}$ & $\begin{array}{c}7- \\
8 \mathrm{p} \\
\mathrm{m}\end{array}$ \\
\hline 2 wheeler & 300 & 327 & 256 & 290 & $\begin{array}{c}42 \\
6\end{array}$ & 322 \\
\hline $\begin{array}{c}4 \text { wheele } \\
\mathrm{r}\end{array}$ & 175 & 147 & 127 & 149 & $\begin{array}{c}20 \\
9\end{array}$ & 252 \\
\hline $\begin{array}{c}\text { Auto } \\
\text { ricksaw }\end{array}$ & 15 & 32 & 24 & 36 & 17 & 39 \\
\hline Bus & 12 & 19 & 18 & 21 & 11 & 16 \\
\hline lcv/lmv & 21 & 17 & 9 & 16 & 4 & 9 \\
\hline $\begin{array}{c}\text { Others(t } \\
\text { ru } \\
\text { cks })\end{array}$ & 0 & 0 & 0 & 0 & 0 & 3 \\
\hline Total & 523 & 542 & 434 & 512 & 671 & 631 \\
\hline
\end{tabular}

Table2: Day 2 count.

\section{Interpretation of Data}

Average traffic in 8-9am: $552+523 / 2=538$

Average traffic in9-10am:533+542/2=538

Average traffic in $1-2 \mathrm{pm}: 494$

Average traffic in 2-3pm:486

Average traffic in6-7pm:690
Average traffic in7-8pm: 657

Max traffic $=690$ and Min traffic $=486$

Now we know that traffic is very heterogeneous. therefore it can vary, although we need to find the peak hour traffic for our analysis and it is during morning or evening when most of people are going to or coming back from their work.

Rush hour may be 6-10 am (6:00-10:00) and 6-8 pm (18:0020:00) Therefore our analysis is much correct up to this point. Now we need to find Average daily traffic (ADT).

We may calculate 24 hour traffic to find ADT but due to lockdown (covid-19) we will make some correct approximation.

We know that peak hour traffic is $8-10 \%$ of ADT.

Minimum ADT will be ( $8 \%$ ) between 4860-6075.

Maximum ADT will be (10\%) between 6900-8625

Here we will assume the maximum traffic and calculate capacity from that. And then compare it with theoretical capacity.

Now \%classification of different vehicles.

Here we will use the basic formula $\%$ of particular vehicle:

No of that particular vehicles counted/ total no of vehicles surveyed

Total number of vehicles counted $=6801$

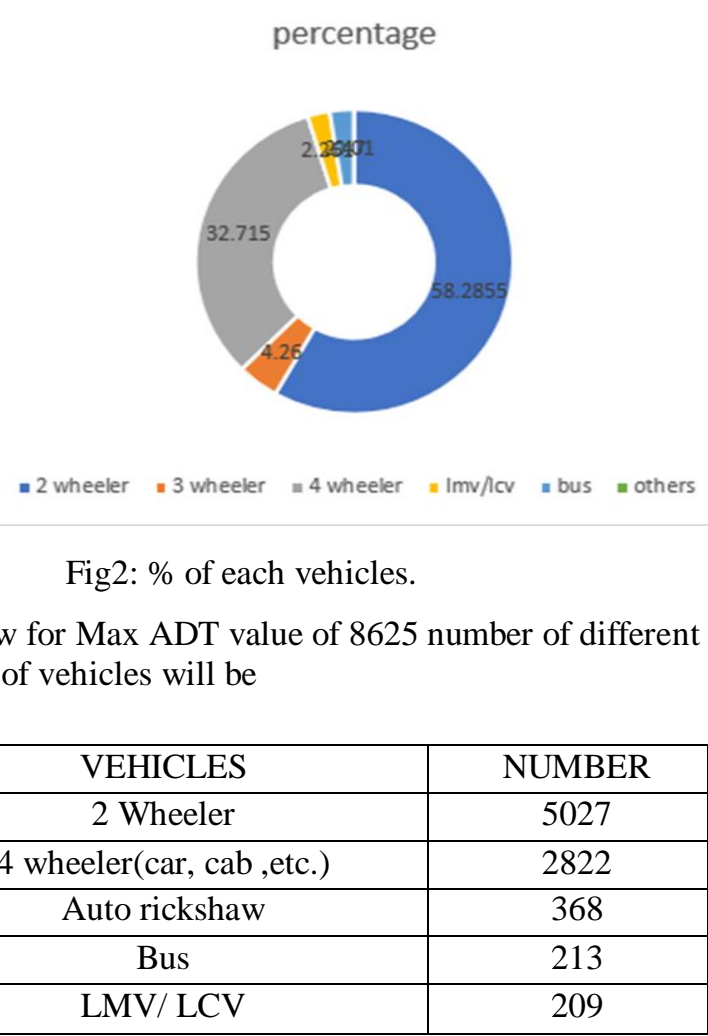

Table3: Number of Vehicles for Maximum ADT. 
2. PCU Measurement.

Now since vehicles have different dimensions and weight, therefore we will convert them into same unit called PCU.Also PCU depends on velocity and the space occupied by vehicles

Here we will use PCU formula suggested by Chandra and Kumar (2003) i.e.

$\mathrm{PCU}=\left(\mathrm{V}_{\mathrm{c}} / \mathrm{V}_{\mathrm{i}}\right) \div\left(\mathrm{A}_{\mathrm{c}} / \mathrm{A}_{\mathrm{i}}\right) \quad$ - ( Equa. 1$)$

$\mathrm{PCU}=$ passenger car unit value of $\mathrm{i}^{\text {th }}$ type vehicle

Speed ratio of the car to the $i^{\text {th }}$ vehicle $V_{c} / V_{i}$

Space ratio of the car to the $i^{\text {th }}$ vehicle is $A_{c} / A_{i}$

$\mathrm{V}_{\mathrm{c}}=$ speed of car in kilometer per hour.

$\mathrm{Vi}=$ speed of $\mathrm{i}^{\text {th }}$ vehicle in kilometer per hour

$\mathrm{A}_{\mathrm{c}}=$ projected rectangular area of a car in meter square. $A_{i}=$ projected rectangular area of $i^{\text {th }}$ vehicle in meter square

Now we need the velocity and area of different type of vehicles. Here since we cannot find out the velocity of all the vehicles included in survey, therefore we will take a sample of vehicles from this survey to find out velocity and projected area. Now to find out velocity of vehicles of the sample taken, we find there velocity using a simple formula ... velocity $=$ dis/ time. and we know the stretch of road i.e $750 \mathrm{~m}$ and then using stopwatch we find out the time taken by the vehicles to cross that stretch. in this way we. find out the velocity of selected vehicles:

Here we took a sample of 240 vehicles i.e.120 (40morning +40 afternoon+40evening traffic) on 1st day count and 120 on $2^{\text {nd }}$ day count.

\begin{tabular}{|l|l|l|l|l|l|}
\hline \multicolumn{5}{|c|}{$18 / 02 / 2020$} \\
\hline $\begin{array}{l}\text { VEHIC } \\
\text { LES }\end{array}$ & $\begin{array}{l}\text { NUM } \\
\text { BER }\end{array}$ & $\begin{array}{l}\text { MORN } \\
\text { ING }\end{array}$ & $\begin{array}{l}\text { AFTERNO } \\
\text { ON }\end{array}$ & $\begin{array}{l}\text { EVENI } \\
\text { NG }\end{array}$ & $\begin{array}{l}\text { V } \\
\text { avg } \\
\text { of } \\
\text { day }\end{array}$ \\
\hline $\begin{array}{l}\text { 2- } \\
\text { Wheele } \\
\text { r }\end{array}$ & 20 & 39.30 & 34.50 & 33.30 & 35.70 \\
\hline $\begin{array}{l}4 \\
\text { wheeler }\end{array}$ & 14 & 44.50 & 39.70 & 35.25 & $\begin{array}{l}39.81 \\
6\end{array}$ \\
\hline $\begin{array}{l}\text { Auto } \\
\text { ricksha } \\
\text { W }\end{array}$ & 2 & 31.70 & 28.50 & 28.20 & 29.47 \\
\hline $\begin{array}{l}\text { LCV } \\
\text { Bus }\end{array}$ & 2 & 33.50 & 30.30 & 27.55 & $\begin{array}{l}30.43 \\
3\end{array}$ \\
\hline
\end{tabular}

Table4: Average velocity in day 1

\begin{tabular}{|l|l|l|l|l|l|}
\hline \multicolumn{5}{|c|}{ 20/02/2020 } & \\
\hline & \multicolumn{5}{|c|}{ V avg( km/hr. } \\
\hline $\begin{array}{l}\text { VEHIC } \\
\text { LES }\end{array}$ & $\begin{array}{l}\text { NUMB } \\
\text { ER }\end{array}$ & $\begin{array}{l}\text { MORINI } \\
\text { NG }\end{array}$ & $\begin{array}{l}\text { AFTERNO } \\
\text { ON }\end{array}$ & $\begin{array}{l}\text { EVENI } \\
\text { NG }\end{array}$ & $\begin{array}{l}\text { V avg } \\
\text { of day }\end{array}$ \\
\hline $\begin{array}{l}2- \\
\text { Wheeler }\end{array}$ & 20 & 37.42 & 32.50 & 34.50 & 34.80 \\
\hline $\begin{array}{l}4- \\
\text { Wheeler }\end{array}$ & 14 & 42.18 & 38.75 & 41.40 & 40.77 \\
\hline $\begin{array}{l}\text { Auto } \\
\text { ricksha } \\
\text { W }\end{array}$ & 2 & 34.50 & 30.48 & 32.00 & 32.32 \\
\hline LCV & 2 & 32.40 & 29.42 & 30.40 & 30.74 \\
\hline Bus & 2 & 36.82 & 31.50 & 30.70 & 33.00 \\
\end{tabular}

Table 5: Average Velocities of Vehicles on day 2

Now find the mean velocity of sample taken over 2 days.

\begin{tabular}{|l|l|}
\hline VEHICLES & Mean velocity $(\mathrm{km} / \mathrm{hr})$ \\
\hline 2 wheeler & 35.25 \\
\hline 4 wheeler & 40.293 \\
\hline Auto rickshaw & 30.895 \\
& \\
\hline LCV & 30.5865 \\
\hline Bus & 33.11 \\
\hline
\end{tabular}

Table 6: Mean Velocities of Vehicles

\begin{tabular}{|c|c|c|c|}
\hline VEHICLES & \multicolumn{2}{|c|}{ Dimensions(meter) } & $\begin{array}{l}\text { Projected } \\
\text { Area }(\mathrm{m} 2)\end{array}$ \\
\hline 2-wheeler & 2.29 & 0.99 & 2.261 \\
\hline 4-wheeler & 3.995 & 1.75 & 6.699 \\
\hline $\begin{array}{l}\text { Auto } \\
\text { rickshaw }\end{array}$ & 2.625 & 1.3 & 3.4125 \\
\hline $\mathrm{LCV}$ & $\begin{array}{l}12 \mathrm{ft}(3.65 \\
6)\end{array}$ & ${ }^{6 \mathrm{ft}}(1.828$ & 6.6868 \\
\hline Bus & 10.5 & 2.5 & 26.25 \\
\hline
\end{tabular}

Table 7: Dimensions of Vehicles

Now using (Equa. 1) we will find PCU factor for different vehicles on the selected road.

\begin{tabular}{|l|l|}
\hline VEHICLES & PCU \\
\hline 2-wheeler & 0.385 \\
\hline 4-wheeler & 1 \\
\hline Auto rickshaw & 0.664 \\
\hline LCV & 1.315 \\
\hline Bus & 4.768 \\
\hline
\end{tabular}

Table8: PCU of different vehicles

So now we will calculate total passenger car (PCU) unit on the road section.

Capacity $=2822+1935.395+244.352+274.835+1015.584$

$=6292.166$

$=6293 \mathrm{veh} / \mathrm{day}$ 
This is the actual number of vehicles coming on the road section

Now according to the highway capacity manual (HCM 2000), India on a 2lane max road capacity can be1700vehicles.

\section{PCU comparison}

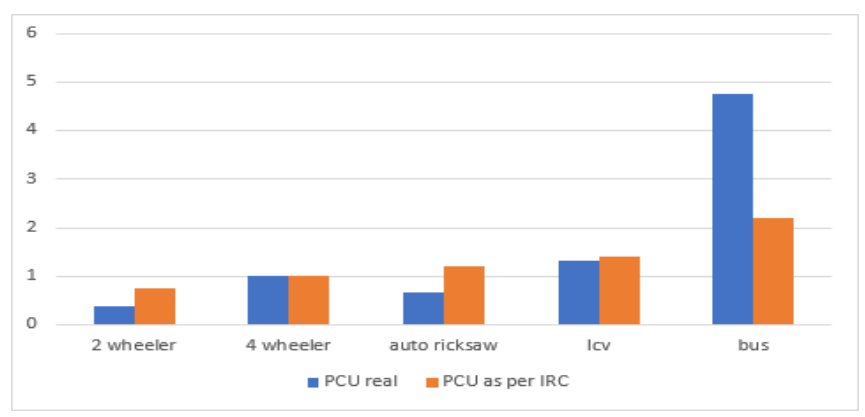

\section{CONCLUSION}

1.We can easily conclude from above result that in any case the maximum capacity will be greater than actual traffic capacity. Therefore, we can say that the road section is not congested. The traffic is free flow.

2.We can see that motorbike, auto rickshaw has less PCU values than that recommended by IRC on urban road while big vehicles like bus have more PCU values than that recommended.

3.It is quite complex to arrive at a specific value of PCU.PCU is not as easy as it seems. It depends highly on

A) traffic data.

B) Nature of vehicles: All motorbikes do not have same PCU as there are many sub-varieties in motorbikes, same is with LCV, cars, buses, etc.

C) it also depends on type of road: since PCU depend on velocity and which depend on the with and condition of the road. Like on less width road small vehicles move relatively faster than on highway

4. we can also say that on urban roads speed differential is quite less therefore PCU depends highly on the physical dimensions of vehicles.

\section{ACKNOWLEDGEMENT}

On the very outset of this report, we would like to extend our sincere and heartfelt obligation towards all the people who have helped us in this endeavor.

We are ineffably indebted to Prof. Narad Muni Prasad for his conscientious guidance, exceptional mentoring and constant monitoring to accomplish this assignment. We would also express our sincere thanks to the Head of Department (HOD), Civil Engineering Mr. Narendra Dev for providing us the opportunity to work on the topic for our B. Tech Major Project.

We would also like to extend our sincere gratitude to the Department of Civil Engineering, for giving us the opportunity to execute this project, which is an integral part of the curriculum in B. Tech program at Delhi Technological University.

\section{REFERENCE}

[1] Mehar, Arpan \& Chandra, Satish \& Senathipathi, Velmurugan. (2014). Passenger Car Units at Different Levels of Service for Capacity Analysis of Multilane Interurban Highways in India. Journal of Transportation Engineering. 140. 81-88. 10.1061/(ASCE)TE.1943-5436.0000615.

[2] K.Smitha Suguna Leela, "OUTER RING ROAD TRAFFIC ANALYSIS AND PREDICTION", International Journal of Creative Research Thoughts (IJCRT), ISSN:2320-2882, Volume.6, Issue 1, pp.322-326, February 2018.

[3] Botswana Guideline 9- Traffic Data Collection and Analysis (2004)

[4] IRC: 106- 1990 Guidelines for capacity of urban roads in plain area.

[5] Rajesh Gajjar, Divya Mohandas,Critical Assessment of Road Capacities on Urban Roads - A Mumbai Casestudy,Transportation Research Procedia,Volume 17,2016,Pages 685-692,ISSN 2352-1465,

[6] Roh, Chang-Gyun \& Park, Bum-Jin \& Kim, Jonghoon. (2017). Impact of Heavy Vehicles on Highway Traffic Flows: Case Study in the Seoul Metropolitan Area. Journal of Transportation Engineering, Part A: Systems. 143. 05017008. 10.1061/JTEPBS.0000077.

[7] T. pavanaram, M. Ramamohana Rao, Chandra Shekhar Gupta, k Srinivasulu, Traffic study and Pavement Evaluation Strength survey, Vijaywada, Andhra Pradesh, 2018.

[8] S.D.Ghodmare, A. (2017). Development of PCU Value of Vehicle under mix Nature Traffic Condition in Cities on Congested Highways. International Journal of Engineering and Computer Science, ISSN:2319-7242 volume 3, 2014.

[9] Wang J, Mao Y, Li J, Xiong Z, Wang WX (2015) Predictability of Road Traffic and Congestion in Urban Areas. PLOS ONE 10(4): e0121825.

[10] Kadiyali L.R, (1988) Traffic Engineering and Transportation Planning, Khanna Publishers New Delhi.

[11] Khanna S. K, and Justo, C.E.G (2001). "Highway Engineering", 8thEdition, Nemchand and Bros, Civil Lines, Publishers, Roorkee 